\title{
Effect of substituents on the excited-state dynamics of the modified DNA bases 2,4-diaminopyrimidine and 2,6-diaminopurine $\dagger$
}

\author{
Zsolt Gengeliczki, ${ }^{a}$ Michael P. Callahan, ${ }^{c}$ Nathan Svadlenak, ${ }^{c}$ \\ Csaba István Pongor, ${ }^{b}$ Bálint Sztáray, ${ }^{b d}$ Leo Meerts, ${ }^{g}$ Dana Nachtigallová,*e \\ Pavel Hobza, ${ }^{e}$ Mario Barbatti, ${ }^{f}$ Hans Lischka ${ }^{* f}$ and Mattanjah S. de Vries ${ }^{* c}$
}

Received 1st September 2009, Accepted 9th February 2010

First published as an Advance Article on the web 8th April 2010

DOI: $10.1039 / \mathbf{b} 917852 \mathrm{j}$

To explore the excited state dynamics of pyrimidine derivatives, we performed a combined experimental and theoretical study. We present resonant two-photon ionization (R2PI) and IR-UV double resonance spectra of 2,4-diaminopyrimidine and 2,6-diaminopurine seeded in a supersonic jet by laser desorption. For 2,4-diaminopyrimidine $\left(S_{0} \rightarrow S_{1} 34459 \mathrm{~cm}^{-1}\right)$, we observed only the diamino tautomer with an excited state lifetime bracketed between experimental limits of 10 ps and 1 ns. For 2,6-diaminopurine, we observed two tautomers, the $9 \mathrm{H}-\left(\mathrm{S}_{0} \rightarrow \mathrm{S}_{1} 34881 \mathrm{~cm}^{-1}\right)$ and $7 \mathrm{H}-\left(\mathrm{S}_{0} \rightarrow \mathrm{S}_{1} 32215 \mathrm{~cm}^{-1}\right)$ diamino forms, with excited state lifetimes of $6.3 \pm 0.4 \mathrm{~ns}$ and $8.7 \pm 0.8 \mathrm{~ns}$, respectively. We investigated the nature of the excited state of 2,4-diaminopyrimidine by means of multi-reference ab initio methods. The calculations of stationary points in the ground and excited states, minima on the $S_{0} / S_{1}$ crossing seam and connecting reaction paths show that several paths with negligible barriers exist, allowing ultrafast radiationless deactivation if excited at energies slightly higher than the band origin. The sub-nanosecond lifetime found experimentally is in good agreement with this finding.

\section{Introduction}

Gas phase laser spectroscopy provides the means to study the intrinsic properties of biologically relevant molecules in isolation. Such studies on RNA and DNA bases have revealed unique photophysical properties that are sensitive to subtle structural differences. In many cases, the biologically most relevant tautomeric form has a sub picosecond excited state lifetime, while other tautomeric forms of the same compound are much longer lived., ${ }^{1,2}$ We have even found that the Watson-Crick structure, adopted by the guanine-cytosine

${ }^{a}$ Department of Chemistry, Stanford University, Stanford, CA 94305-5080,USA. E-mail: dana.nachtigallova@uochb.cas.cz. hans.lischka@univie.ac.at,devries@chem.ucsb.edu;

Fax: (+1) 805-893-4120; Tel: (+1) 805-893-5921

${ }^{b}$ Institute of Chemistry, Eötvös Loránd University Budapest,

1/A Pázmány P. stny., Hungary 1117

${ }^{c}$ Department of Chemistry and Biochemistry, University of California,

Santa Barbara, CA-93106-9510, USA

${ }^{d}$ Department of Chemistry, University of the Pacific, Stockton, CA-95211, USA

${ }^{e}$ The Institute of Organic Chemistry and Biochemistry,

Flemingovo nám., 2, 16610 Praha 6, Czech Republic

${ }^{f}$ Institute for Theoretical Chemistry, University of Vienna,

Waehringerstrasse 17, A1090 Vienna, Austria

${ }^{g}$ Molecular and Biophysics Group, Institute for Molecules and

Materials, Radboud University, 6500 GL Nijmegen, The Netherlands

$\dagger$ Electronic supplementary information (ESI) available: The calculated vertical ionization potentials for all the 2,4-diaminopyrimidine tautomers (Fig. S1 and Table S1). The vertical excitation energies calculated at the RICC2 method with various basis sets (Table S2). The interpolation curves between the S1min_C2 and S1min_C6 minima towards various MXS structures calculated at the CASSCF and MR-CISD(17) + Q methods (Fig. S2). This material is available free of charge on the Internet. See DOI: $10.1039 / \mathrm{b} 917852 \mathrm{j}$
(GC) base pair in DNA, appears to have a much shorter excited state lifetime than other structures of the same base pair. ${ }^{3}$ Theoretical models explain these short lifetimes by a rapid internal conversion in which the excited state $\left(S_{1}\right)$ is coupled to the ground state $\left(\mathrm{S}_{0}\right)$ via pathways with no or a very small barrier leading to conical intersections. ${ }^{4}$ For the longer lived structures, small differences in relative energies cause the existence of barriers that lead to discrete spectra and lifetimes that can be two orders of magnitude longer. This rapid internal conversion pathway provides selected isomers with significantly enhanced photochemical stability, absent in the other longer lived structures. It is conceivable that these differences between excited state lifetimes of different bases and base-pair structures could have played a significant role in prebiotic chemistry. ${ }^{3}$

The five naturally occurring nucleic acid bases ${ }^{5-9}$ exhibit an ultrafast excited state relaxation in the gas phase. For DNA bases it has been shown ${ }^{1,10-24}$ that the energetically lowest conical intersections responsible for fast deactivation to the ground state are characterized by ring puckering modes. The most favorable ring puckering conical intersections result from the change of the HC6C5R $\left(\mathrm{R}=\mathrm{H}, \mathrm{CH}_{3}\right)$ dihedral angle in uracil and thymine and the $\mathrm{HN} 1 \mathrm{C} 2 \mathrm{H}$ dihedral angle in adenine. This model also explains why by contrast 2-aminopurine, in which the $\mathrm{C} 2$ position is substituted by the amino group, has a long excited state lifetime and strong fluorescence. ${ }^{25-27}$ Alternatively, the puckering at the C6 atom was also suggested to be responsible for adenine relaxation. ${ }^{28}$

Recently, surface-hopping dynamics studies of 4-aminopyrimidine (4-APy) $)^{29-31}$ and $9 \mathrm{H}$-adenine ${ }^{24}$ showed that while the former relaxes into the ground state via different conical 
intersections formed by puckering at the C6, N1, and C2 atoms, the latter relaxes exclusively through conical intersections formed by puckering at the $\mathrm{C} 2$ atom. This demonstrates the role of hindering imposed by the imidazole ring of adenine. Fig. 1 shows the structures and numbering of these two compounds as well as the 2-amino substituted analogues studied in the present paper, 2,4-diaminopyrimidine (2,4-DAPy) and 2,6-diaminopurine (2,6-DAPu). Fig. $1 \mathrm{~b}$ and $\mathrm{c}$ show the lowest energy tautomers for the latter two compounds. One may expect that a structural modification of the pyrimidine ring in each of these molecules affects locations and accessibility of conical intersections. In particular, amino-substitution in the $\mathrm{C} 2$ position should affect conical intersections associated with puckering at that site, while addition of an imidazole ring to form purine bases should affect conical intersections associated with ring deformation at the $\mathrm{C} 5$ and $\mathrm{C} 6$ sites. Thus, in 2,4-DAPy puckering at the $\mathrm{C} 2$ position is affected, and in 2,6-DAPu puckering at both positions is modified. Therefore, it is especially useful to compare the photochemistry of these compounds.

In addition to these theoretical aspects there exists a further motivation for studying 2,4-DAPy and 2,6-DAPu bases. Joyce et al. have proposed that alternative nucleobases, which may form base pairs with geometries similar to Watson-Crick structures, may have played a role in constructing the first genetic code on the early Earth. ${ }^{32}$ Xanthine and 2,4-DAPy can form an unnatural base pair that fits the Watson-Crick geometry and can be incorporated into RNA and DNA by polymerases. ${ }^{33-36}$ Another base pair mimicking the WatsonCrick geometry is formed by 2,6-diaminopurine and uracil. For each of these molecules, there exists a plausible, prebiotic synthetic route. $^{37-41}$

Purines and pyrimidines can exist in a variety of different tautomeric forms, which can exhibit drastically different photophysical behavior. ${ }^{42-45}$ Therefore, investigating the effects of modification of the hetero-aromatic ring, in particular a possible immobilization of certain parts of this ring by its substitution at locations affecting the accessibility of conical intersections can refine our understanding of the intrinsic photostability of these alternative nucleobases. ${ }^{9,29-31}$

In the series of prebiotic and alternate RNA/DNA bases, we previously studied the nucleobase xanthine. ${ }^{46}$ In this paper we report the one-color R2PI spectra of 2,4-diaminopyrimidine (2,4-DAPy) and 2,6-diaminopurine (2,6-DAPu) as well as their IR-UV double resonance spectra. Because pyrimidine derivatives have relatively high ionization energies unavailable by two-photon ionization, ${ }^{47}$ we measured the ionization energy of 2,4-DAPy by photoelectron spectroscopy to rule out threephoton resonant ionization schemes. To explain the nature and dynamics of the excited state of 2,4-DAPy, we characterized the stationary points in its ground and excited states and its $\mathrm{S}_{1} / \mathrm{S}_{0}$ conical intersections (minima on the crossing seam, MXS) as well as pathways to internal conversion by means of CASSCF, MR-CISD, and CASPT2 methods.

\section{Experimental and theoretical methods}

2,4-Diaminopyrimidine and 2,6-diaminopurine were purchased from Sigma-Aldrich and used without further purification.
The experimental setups have been described in detail elsewhere and only brief descriptions will be given here. ${ }^{48,49}$

\section{Laser spectroscopy}

The desorption laser, a Nd:YAG operating at $1064 \mathrm{~nm}$, is attenuated to $1 \mathrm{~mJ} \mathrm{~cm}{ }^{-2}$ and focused to a spot approximately $0.5 \mathrm{~mm}$ diameter within $2 \mathrm{~mm}$ in front of the nozzle orifice. We translate the sample in order to expose fresh sample to successive laser shots. The nozzle consists of a pulsed valve with a nozzle diameter of $1 \mathrm{~mm}$ and a backing pressure of $6 \mathrm{~atm}$ of argon drive gas. The neutral molecules are skimmed and then ionized with a frequency doubled dye laser. We detect the ions in a reflectron time-of-flight mass spectrometer.

We obtain resonant two-photon ionization (R2PI) spectra by monitoring mass selected peaks while tuning the one-color, two-photon ionization wavelength. We measure UV-UV double resonance spectra with two laser pulses separated in time by $200 \mathrm{~ns}$. Ionization laser intensities are approximately $3 \mathrm{~mJ}$ pulse $\mathrm{s}^{-1}$ and are strongly attenuated to avoid saturation. The first pulse serves as a "burn" pulse, which removes the ground state population and causes depletion in the ion signal of the second "probe" pulse, provided both lasers are tuned to a resonance of the same tautomer. IR-UV double resonance spectra are obtained in an analogous way with the burn laser operating in the near-IR region. IR frequencies are produced in an OPO setup (LaserVision) pumped by a Nd:YAG laser operating at its fundamental frequency. For this work, we operated within the range of $3200-3800 \mathrm{~cm}^{-1}$, which encompasses $\mathrm{NH}$ and $\mathrm{OH}$ modes. Typical IR intensities in the burn region are $12 \mathrm{~mJ}$ pulse $\mathrm{s}^{-1}$ and the bandwidth is $3 \mathrm{~cm}^{-1}$. Excited state lifetimes are measured in a two-color, two-photon ionization experiment. The pump and probe photons are separated by a time delay of $100 \mathrm{ps}$ to $100 \mathrm{~ns}$, and the ion signal is recorded as a function of the time delay. The lifetime of the excited state is given as the time constant of the exponential decay of the ion signal.

\section{Photoelectron spectroscopy}

He-I photoelectron spectra were recorded on a custom-built ATOMKI ESA-32 instrument. ${ }^{49}$ The spectrometer is equipped with a Leybold-Heraeus UVS 10/35 high-intensity helium discharge photon source. The sample was introduced into the ionization chamber via solid inlet probe at an elevated temperature of $260{ }^{\circ} \mathrm{C}$. The spectra were calibrated against $\mathrm{Ar}$ ${ }^{2} \mathrm{P}_{3 / 2}$ and ${ }^{2} \mathrm{P}_{1 / 2}$ peaks. The maximum error in the ionization energies is estimated to be less than $0.04 \mathrm{eV}$, and the energy resolution of the He-I spectra was better than $40 \mathrm{meV}$ (FWHM) as determined from $\mathrm{Ar} 3 \mathrm{p}$ ionizations. In the extraction of the vertical ionization potentials, Shirley background and pseudo-Voigt peaks were fitted on the experimental spectra. The adiabatic ionization potential can be estimated as the onset of the ionization and has a somewhat higher uncertainty than the vertical ionization potentials.

\section{Quantum chemical calculations}

Identifying the tautomers. To assign the IR-UV double resonance spectra, we computed the structures of the possible tautomers using density functional theory (DFT) and ab initio 
(a)<smiles>Nc1ccncn1</smiles>

4-aminopyrimidine<smiles></smiles>

2,4-diaminopyrimidine<smiles>Nc1ncnc2[nH]cnc12</smiles>

$9 \mathrm{H}$-adenine

(b)<smiles>Nc1nc(N)c2nc[nH]c2n1</smiles>

\section{2,6-diaminopurine}
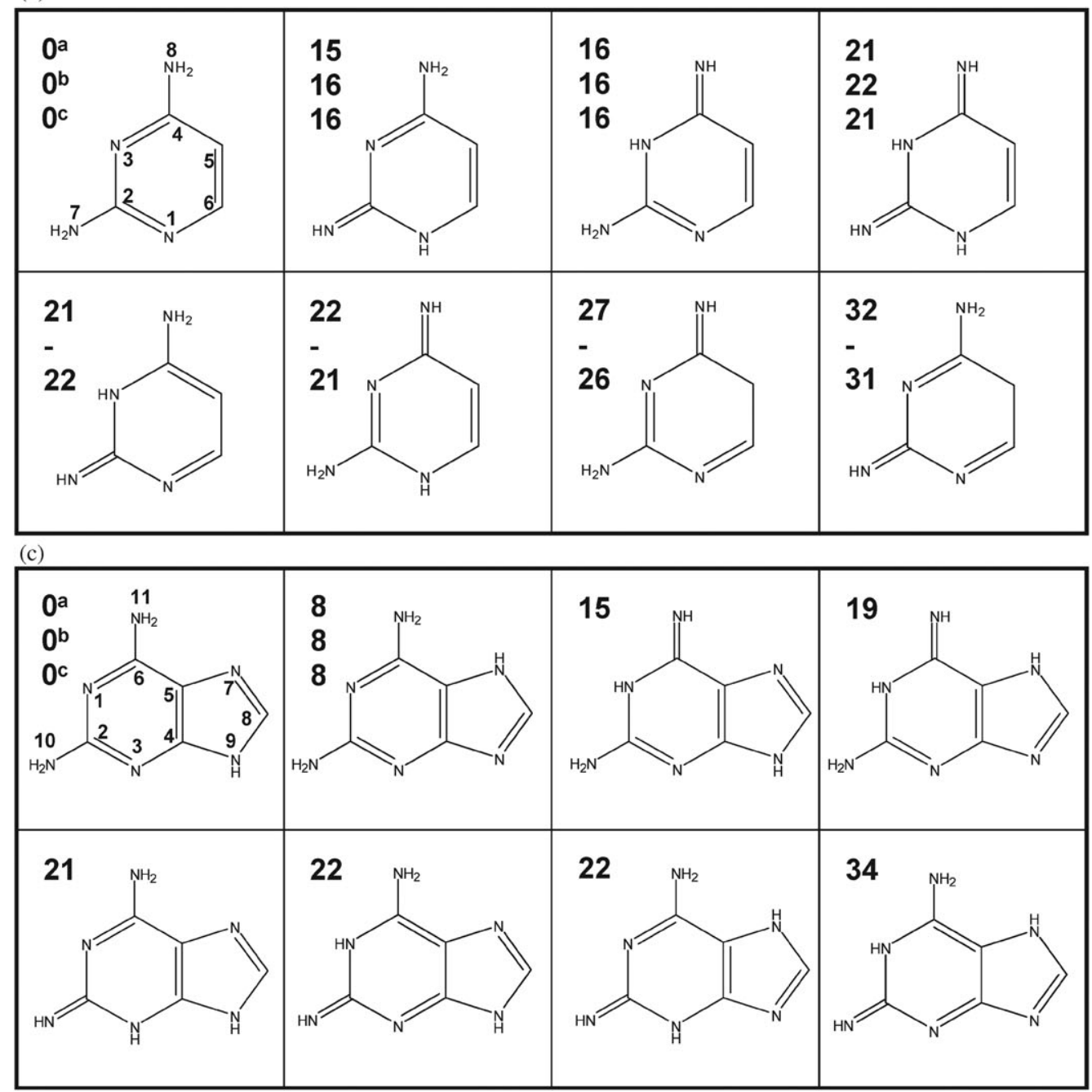

Fig. 1 (a) Structures of the four related compounds discussed in the text. Calculations predict conical intersections for 4-Apyr due to ring deformations at positions $\mathrm{C} 2$ and $\mathrm{C} 6, \mathrm{C} 5$, and N1. Amino substitution in the $\mathrm{C} 2$ position affects the conical intersection associated with that position, while addition of the 5 membered ring for the purines affects the conical intersections associated with ring deformation in the other positions. (b) The tautomers and numbering scheme of 2,4-diaminopyrimidine. Relative energies obtained at the (a) B3LYP/6-311+G(2d,p) (b) MP2(FC) $/ 6-311+\mathrm{G}(2 \mathrm{~d}, \mathrm{p})$ and (c) G3 levels are in $\mathrm{kcal} \mathrm{mol}^{-1}$. (c) The tautomers and numbering scheme of 2,6-diaminopurine. Relative energies obtained at the (a) B3LYP/6-311+G(2d,p) (b) MP2(FC)/6-311+G(2d,p) and (c) G3 levels are in kcal mol ${ }^{-1}$. 
methods. We combined Becke's three-parameter hybrid functional $^{50}$ with the Lee-Yang-Parr exchange correlation functional $^{51,52}$ (B3LYP) and the $6-311+\mathrm{G}(2 \mathrm{~d}, \mathrm{p})$ basis set. ${ }^{53,54}$ We used the same basis set in frozen core second order Møller-Plesset perturbation (MP2) calculations. ${ }^{55-60}$ We verified the equilibrium structures by the absence of imaginary vibrational frequencies. The calculated vibrational frequencies were scaled by $0.9618^{61}$ (DFT) or $0.9496^{62}$ (MP2) to account for electronic structure method deficiency and anharmonicity. To establish the relative energies of the tautomers, we also applied the Gaussian-3 (G3) composite method. ${ }^{63}$

Ionization energies. To assign the photoelectron spectrum, we calculated ionization energies for 2,4-diaminopyrimidine, using the B3LYP functional and 6-311+G(2d,p) basis set. We calculated the adiabatic ionization potential as the energy difference between the equilibrium geometries of the ionic state and the ground state neutral molecule, estimating the first vertical ionization energy as the difference between the energies of the ionic state and the neutral molecule at the equilibrium geometry of the latter. Then, at the equilibrium geometry of the ion, we performed time-dependent DFT (TD-DFT) calculations to compute the vertical excitation energies of the ion. ${ }^{64-66}$ Vertical ionization energies are then the sum of the adiabatic ionization energies and vertical excitation energies of the ion. We also performed outer valence Green's function (OVGF) calculations with the 6-311+G(2d,p) basis set at the equilibrium geometries of the neutral tautomers obtained in the DFT calculations. ${ }^{67-74}$ All calculations were carried out using the Gaussian 03 Rev. C. 02. quantum code package. ${ }^{75}$

Excited state investigations of 2,4-diaminopyrimidine. We performed the calculations using the complete active space self-consistent field (CASCCF) and multi-reference interaction (MR-CI) methods for 2,4-DAPy. In the MR-CI approach, single and double excitations from the CI reference space are included (MR-CISD) and generalized interacting space restrictions are adopted. ${ }^{76} \mathrm{We}$ constructed the orbital space for CASSCF wavefunctions using 14 electrons in 10 orbitals, i.e. composed of eight $\pi$ orbitals and two lone pairs located on the ring nitrogen atoms. We used a state-averaging procedure using three states (SA-3) at the CASSCF level throughout the calculations. Based on the CAS $(14,10)$, we constructed the MR-CISD reference space by moving orbitals with natural occupation larger than 0.9 and smaller than 0.1 to the doubly occupied and virtual spaces, respectively, resulting in a MR-CI reference space composed of six electrons in five orbitals (MR-CISD(6,5)). All single and double excitations from this reference space were allowed; all core orbitals were frozen. To reduce the computational cost of the calculations, up to a total number of 17 doubly occupied orbitals were frozen in MRCI calculations of the reaction paths. We tested this procedure against full calculations for selected typical examples, taking into account the size-consistency effects by means of Pople's correction method, indicated by $+\mathrm{Q} .{ }^{77}$ We used the 6-31G** basis set throughout the calculations. ${ }^{78,79}$ For comparison and to verify the reliability of the applied basis set we also applied the complete active space self-consistent-field second-order perturbation theory (CASPT2) method $^{80,81}$ with the same reference CAS space and resolution-of-identity coupled cluster to the second-order (RICC2) ${ }^{82,83}$ method.

We determined the minima on the ground and excited $S_{1}$ surfaces and on the seam of conical intersections (MXS) by the CASSCF $(14,10)$ method. We constructed reaction paths between structures of the $S_{1}$ minima and the MXSs using the method of linear interpolation of internal coordinates (LIIC). The CASSCF and MR-CISD energies of relevant points of the reaction paths were plotted as a function of mass-weighted distances between each point of the path and the $S_{1}$ minimum. We also determined the structures of the transition states for selected reaction paths using the $\operatorname{CASSCF}(14,10)$ method. We confirmed the character of the stationary point by Hessian calculations within a selected space of internal coordinates relevant for the ring puckering modes.

We simulated the absorption spectrum of 2,4-DAPy employing the RICC2 and CASSCF methods, using the Gaussian broadening method described by Barbatti et al. ${ }^{84} \mathrm{We}$ used the same active space and number of states in the average procedure as specified above. We generated five hundreds points by a Wigner distribution in the ground vibrational state of the ground electronic state, computed based on a Wigner distribution for the ground vibrational and electronic state, taking each nuclear degree of freedom within the harmonic approximation. The Wigner distribution composed of 500 different geometries was projected onto the excited state by multiplying it by the Einstein coefficient B computed for each point. We used a phenomenological broadening of $0.05 \mathrm{eV}$.

We performed the optimization of conical intersections using the analytic gradient and non-adiabatic coupling vectors ${ }^{85-89}$ available in the COLUMBUS program system. ${ }^{90-92}$ We performed the CASPT2 calculations with the MOLCAS program package $^{93-95}$ and RICC2 computations were performed using the Turbomole program system. ${ }^{96}$ The absorption spectrum was simulated using the NEWTON-X program package. ${ }^{84,97}$

\section{Results and discussion}

\section{2,4-Diaminopyrimidine R2PI and IR-UV double resonance spectroscopy}

Fig. 2 shows the R2PI spectrum of 2,4-diaminopyrimidine in the wavelength range of $34350-35100 \mathrm{~cm}^{-1}$. In a one-color experiment, we might not be able to observe the $\mathrm{S}_{1} \leftarrow \mathrm{S}_{0}$ origin transition if the ionization potential of the molecule is too high. Therefore, we determined the ionization potential by photoelectron spectroscopy, as detailed below. For 2,4-diaminopyrimidine we found a relatively low vertical ionization potential of $8.30 \pm 0.05 \mathrm{eV}$ and an adiabatic ionization potential of $7.86 \pm 0.05 \mathrm{eV}$, which corresponds to $33471 \mathrm{~cm}^{-1}$ and $31698 \mathrm{~cm}^{-1}$ photon wave numbers, respectively, in terms of the one-color experiments. We, therefore, tentatively assign the red-most peak at $34459 \mathrm{~cm}^{-1}$ as the $S_{1} \leftarrow S_{0}$ origin transition. If this assignment is correct, the intensity distribution in the spectrum suggests significant geometric deformation of the excited state relative to the ground state.

The R2PI spectrum consists of a single tautomer, based on IR-UV double resonance experiments at different UV probe wavelengths, as detailed below. Fig. 3 shows the IR spectrum, 


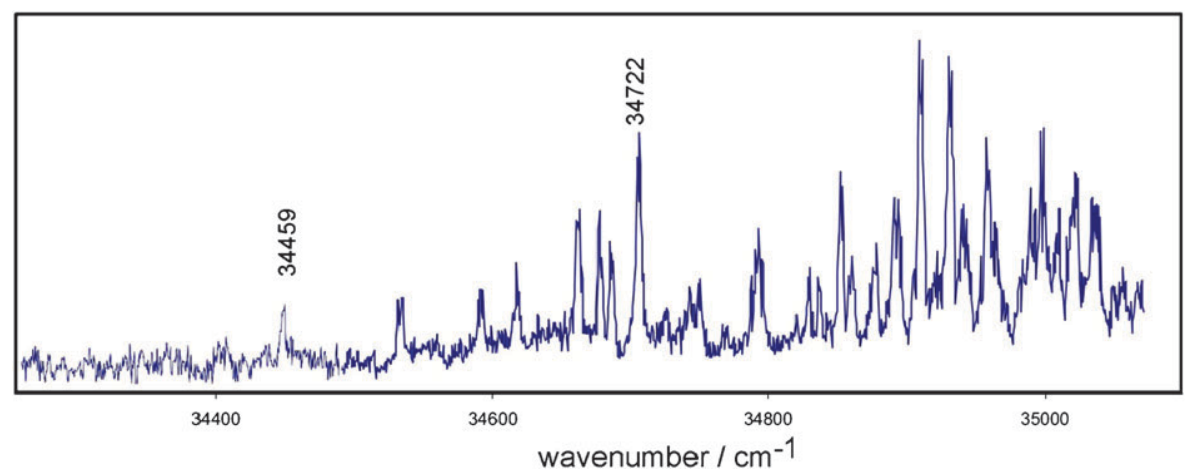

Fig. 2 The R2PI spectrum of 2,4-diaminopyrimidine. The $S_{1} \leftarrow S_{0}\left(\pi \pi^{*}\right)$ origin is at $34459 \mathrm{~cm}^{-1}$. Data were not corrected for variations in laser intensities.

obtained at a probe frequency of $34516 \mathrm{~cm}^{-1}$. The spectrum shows four distinct peaks in the frequency range of $3400-3600 \mathrm{~cm}^{-1}$. By fitting the experimental data with a sum of Lorentzian curves, we extracted vibrational frequencies of $3452,3464,3563$, and $3578 \mathrm{~cm}^{-1}$. This indicates the presence of four free $\mathrm{N}-\mathrm{H}$ stretching modes in the molecule and suggests that we observe the diamino form (see Fig. 1b). We computed the relative energies of all tautomers at the B3LYP/ $6-311+\mathrm{G}(2 \mathrm{~d}, \mathrm{p}), \mathrm{MP} 2(\mathrm{FC}) / 6-311+\mathrm{G}(2 \mathrm{~d}, \mathrm{p})$ and G3 levels. At every level the di-amino form was the lowest energy tautomer with the second most stable tautomer at a relative energy $15 \mathrm{kcal} / \mathrm{mol}$ higher than the diamino form. We calculated the vibrational frequencies for all tautomers at the DFT and MP2 levels. The di-amino tautomer provides an excellent match between the calculated and the experimental frequencies. Table 1 summarizes the vibrational frequencies.

To determine that only the diamino tautomer is present in the R2PI spectrum, we set the IR frequency to $3578 \mathrm{~cm}^{-1}$ and scanned the R2PI spectrum again. The IR band at $3578 \mathrm{~cm}^{-1}$ is the most diagnostic band for the diamino tautomer compared with the theoretically calculated IR bands for the other tautomers. The R2PI spectrum obtained while hole burning at this IR frequency showed a complete depletion in the ion signal for the entire spectral range when the IR was on. This result implies that all peaks in the R2PI spectrum are due to the diamino tautomer.

\section{Photoelectron spectroscopy}

Fig. 4 shows the photoelectron spectrum of 2,4-diaminopyrimidine. The adiabatic ionization potential, derived from the onset, is $7.86 \pm 0.05 \mathrm{eV}$. We derived the vertical ionization potentials by fitting the sum of pseudo-Voigt curves on the observed bands. Based on the intensities and the widths of the bands, we find vertical ionization potentials corresponding to six ionic states. An additional experimentally unresolved broad band starts at an onset of $13 \mathrm{eV}$. It is implausible that precise ionization energies can be extracted from the spectrum above $13 \mathrm{eV}$, and we only note that the first maximum of this range is at $13.51 \mathrm{eV}$.

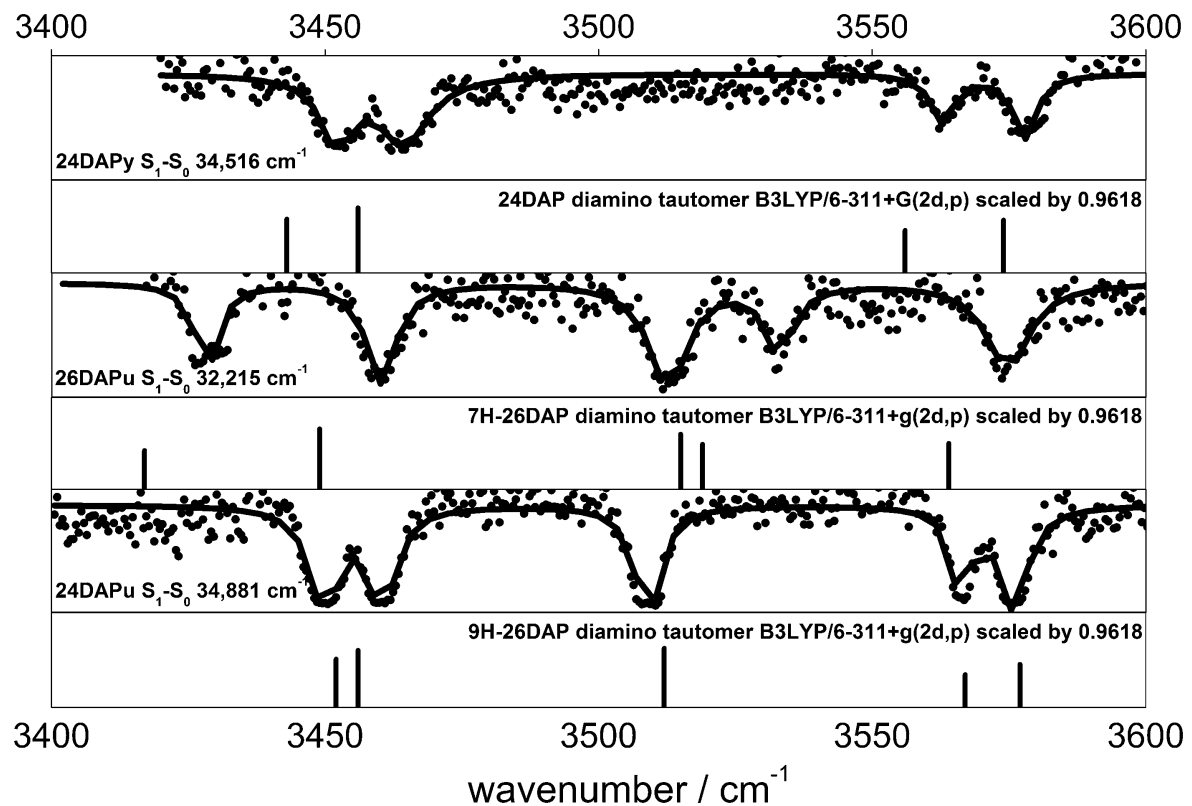

Fig. 3 The IR-UV double resonance spectra of 2,4-diaminopyrimidine and 2,6-diaminopurine in the N-H stretch IR wavelength range. The stick spectra represent the best matching calculated vibrational frequencies at the B3LYP/6-311+G(2d,p) level. A scaling factor of 0.9618 was applied. 
Table 1 Calculated vibrational frequencies for tautomers of 2,4-diaminopyrimidine in the $\mathrm{N}-\mathrm{H}$ region. All frequencies have been scaled and given in $\mathrm{cm}^{-1}$. MP2 scaling factor: 0.9496; B3LYP scaling factor: 0.9618. For numbering scheme, see Fig. 1. For comparison, the experimental vibrational frequencies are $3452,3464,3563$, and $3578 \mathrm{~cm}^{-1}$

\begin{tabular}{|c|c|c|c|}
\hline Tautomer & MP2 $6-311+\mathrm{G}(2 \mathrm{~d}, \mathrm{p}) \omega / \mathrm{cm}^{-1}$ & B3LYP $6-311+\mathrm{G}(2 \mathrm{~d}, \mathrm{p}) \omega / \mathrm{cm}^{-1}$ & Vib. Mode \\
\hline 24DAP & 3532 & 3574 & $\mathrm{~N} 7 \mathrm{H}$ as \\
\hline \multirow[t]{3}{*}{ diamino tautomer } & 3518 & 3556 & $\mathrm{~N} 8 \mathrm{H}$ as \\
\hline & 3410 & 3456 & N7H s \\
\hline & 3400 & 3443 & $\mathrm{~N} 8 \mathrm{H} \mathrm{s}$ \\
\hline \multirow[t]{4}{*}{$1 \mathrm{H}, 7$ imino } & 3527 & 3564 & $\mathrm{~N} 8 \mathrm{H}$ as \\
\hline & 3440 & 3483 & $\mathrm{~N} 1 \mathrm{H}$ \\
\hline & 3403 & 3446 & $\mathrm{~N} 8 \mathrm{H} \mathrm{s}$ \\
\hline & 3351 & 3386 & $\mathrm{~N} 7 \mathrm{H}$ \\
\hline \multirow[t]{4}{*}{$3 \mathrm{H}, 8$ imino } & 3496 & 3534 & $\mathrm{~N} 7 \mathrm{H}$ as \\
\hline & 3403 & 3445 & $\mathrm{~N} 3 \mathrm{H}$ \\
\hline & 3387 & 3431 & N7H s \\
\hline & 3346 & 3380 & $\mathrm{~N} 8 \mathrm{H}$ \\
\hline $1 \mathrm{H}, 3 \mathrm{H}$ & 3467 & 3507 & $\mathrm{~N} 1 \mathrm{H}$ \\
\hline \multirow[t]{3}{*}{7,8 imino } & 3422 & 3469 & $\mathrm{~N} 3 \mathrm{H}$ \\
\hline & 3359 & 3392 & $\mathrm{~N} 10 \mathrm{H}$ \\
\hline & 3344 & 3378 & $\mathrm{~N} 11 \mathrm{H}$ \\
\hline \multirow[t]{4}{*}{$3 \mathrm{H}, 7$ imino } & & 3535 & $\mathrm{~N} 8 \mathrm{H}$ as \\
\hline & & 3454 & $\mathrm{~N} 3 \mathrm{H}$ \\
\hline & & 3435 & $\mathrm{~N} 8 \mathrm{H} \mathrm{s}$ \\
\hline & & 3387 & $\mathrm{~N} 7 \mathrm{H}$ \\
\hline \multirow[t]{4}{*}{$1 \mathrm{H}, 8$ imino } & & 3508 & $\mathrm{~N} 7 \mathrm{H}$ as \\
\hline & & 3492 & $\mathrm{~N} 1 \mathrm{H}$ \\
\hline & & 3411 & $\mathrm{~N} 7 \mathrm{H} \mathrm{s}$ \\
\hline & & 3328 & $\mathrm{~N} 8 \mathrm{H}$ \\
\hline \multirow[t]{4}{*}{$5 \mathrm{H}, 8$ imino } & & 3593 & $\mathrm{~N} 7 \mathrm{H}$ as \\
\hline & & 3465 & N7H s \\
\hline & & 3316 & $\mathrm{~N} 8 \mathrm{H}$ \\
\hline & & 2986 & $\mathrm{CH}$ \\
\hline \multirow[t]{4}{*}{$5 \mathrm{H}, 7$ imino } & & 3559 & $\mathrm{~N} 8 \mathrm{H}$ as \\
\hline & & 3436 & N8H s \\
\hline & & 3345 & $\mathrm{~N} 7 \mathrm{H}$ \\
\hline & & 2972 & $\mathrm{CH}$ \\
\hline
\end{tabular}

Considering the relative energies of the tautomers of 2,4diaminopyrimidine, it is very unlikely that we observe more than one tautomer in the gas phase, even at the applied inlet temperature of $260{ }^{\circ} \mathrm{C}$. However, we performed restricted OVGF calculations at the $6-311+\mathrm{G}(2 \mathrm{~d}, \mathrm{p})$ level for all the possible isomers, employing single point calculations on the DFT equilibrium geometries. The outer valence Green's function method is a useful tool in the assignment of photoelectron spectra of organic molecules. The vertical ionization potentials are usually predicted within $0.3 \mathrm{eV} .{ }^{98} \mathrm{We}$ obtained the best match with the experimental values for the most stable

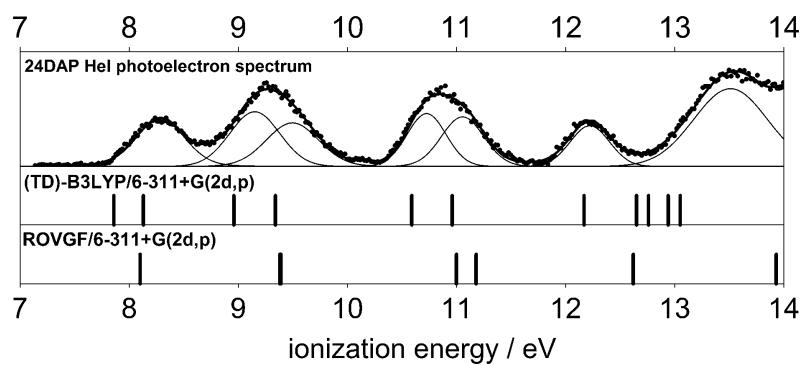

Fig. $4 \mathrm{He}-\mathrm{I}$ photoelectron spectrum of 2,4-diaminopyrimidine. pseudo-Voigt shaped peaks were fitted on the observed bands to extract the vertical ionization potentials. The adiabatic ionization potential was taken as the ionization onset at $7.86 \mathrm{eV}$. The adiabatic and vertical ionization energies were also computed at the (TD)-B3LYP/ $6-311+\mathrm{G}(2 \mathrm{~d}, \mathrm{p})$ and ROVFG/6-311 + G(2d,p) levels and represented by the stick spectra. See text for details. tautomer, the diamino form. Fig. 4 lists the calculated ionization potentials. Photoelectron spectroscopy can also be regarded as a tool for probing the ionic states. To obtain adiabatic and vertical ionization energies for the diamino form, we carried out TD-B3LYP/6-311+G(2d,p) calculations at the equilibrium geometry of the ion. According to both methods, the first peak of the spectrum can be assigned to the ionization of the HOMO, that is, the removal of an electron from the $\pi$ system.

Table 2 lists the adiabatic and the lowest vertical ionization energies. The predicted vertical ionization energies of all the possible tautomers are compared to the experimental spectrum in the Supporting Information (Fig. S1 and Table S1, ESI). $\dagger$

\section{2,6-Diaminopurine R2PI and IR-UV double resonance spectroscopy}

Previously, we reported a resonant two-photon ionization spectrum of 2,6-diaminopurine between $32000 \mathrm{~cm}^{-1}$ and $34000 \mathrm{~cm}^{-1}$ without identifying the observed tautomer. In the present study, we extended the R2PI spectrum up to $35400 \mathrm{~cm}^{-1}$, as shown in Fig. 5. Two groups of peaks can be distinguished, based on hole burning, with possible $S_{1} \leftarrow S_{0}$ origins at $32215 \mathrm{~cm}^{-1}$ and $34881 \mathrm{~cm}^{-1}$, respectively. We carried out IR-UV double resonance experiments on these two possible origins. The resulting IR spectra, shown in Fig. 3, are not identical, indicating the presence of at least two different tautomers in the gas phase. Both spectra exhibit five 
Table 2 Experimental excitation and ionization energies (in $\mathrm{eV}$ ) of 2,4-diaminopyrimidine and 2,6-diaminopurine

2,4-diaminopyrimidine

\begin{tabular}{lll}
\hline Transition & & $h v / \mathrm{eV}$ \\
$\mathrm{S}_{1} \leftarrow \mathrm{S}_{0}$ & & 4.27 \\
$\mathrm{D}_{0} \leftarrow \mathrm{S}_{0}$ & $I E_{\text {ad }}$ & 7.86 \\
& $I E_{\text {vert }}$ & 8.30 \\
\hline
\end{tabular}

7H-2,6-diaminopurine

$\mathrm{S}_{1} \leftarrow \mathrm{S}_{0}$ 3.99

9H-2,6-diaminopurine

$\mathrm{S}_{1} \leftarrow \mathrm{S}_{0}$ 4.32

IR bands. With the UV probe set at $34881 \mathrm{~cm}^{-1}$ IR frequencies appear at $3450,3460,3509,3566$, and $3576 \mathrm{~cm}^{-1}$. These frequencies match very well with the calculated IR frequencies of 2,6-diaminopurine. We assign the peaks at 3566 and $3576 \mathrm{~cm}^{-1}$ to the antisymmetric combinations of the $\mathrm{N}-\mathrm{H}$ stretches in the amino groups, the peaks at 3450 and $3460 \mathrm{~cm}^{-1}$ to the symmetric combinations of the same stretches, and the peak at $3509 \mathrm{~cm}^{-1}$ to either the $\mathrm{N} 9-\mathrm{H}$ or the $\mathrm{N} 7-\mathrm{H}$ stretching mode. A hydrogen atom on the N9 position seems to be more plausible, because it might have a smaller effect on the $\mathrm{N}-\mathrm{H}$ stretching modes of the amino groups, as discussed in the next paragraph.

With the UV probe at $32215 \mathrm{~cm}^{-1}$, the five IR bands appear at $3428,3460,3513,3533$, and $3575 \mathrm{~cm}^{-1}$. When compared to the former IR spectrum, significant red shifts of two peaks are apparent. The peak at $3450 \mathrm{~cm}^{-1}$ is shifted to $3428 \mathrm{~cm}^{-1}$, and the peak at $3566 \mathrm{~cm}^{-1}$ is shifted to $3533 \mathrm{~cm}^{-1}$. If the assignment of the first IR spectrum is correct, this shift can be explained by placing the hydrogen atom for this tautomer on the N7 position instead of the N9 position. That would perturb the $\mathrm{N}-\mathrm{H}$ stretching modes in the $\mathrm{N} 11$ amino group. DFT (B3LYP/6-311+ G(2d,p)) and ab initio (MP2(FC)/ $6-311+G(2 d, p))$ calculations of the vibrational frequencies of the various tautomers support this qualitative assignment. Table 3 shows the comparison of the calculated vibrational frequencies with the experimental values. The two diamino forms provide the best match. Furthermore, when calculating

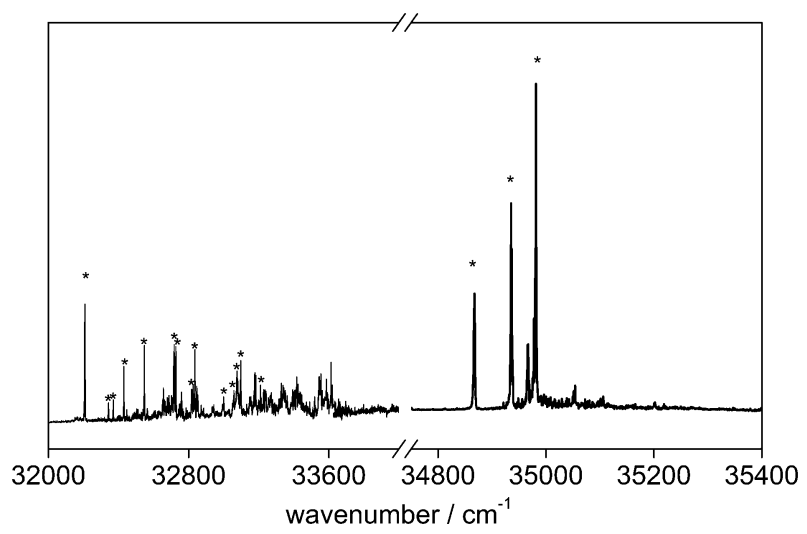

Fig. 5 The R2PI spectra of the $7 \mathrm{H}$ and $9 \mathrm{H}$ tautomers of 2,6diaminopurine. The $S_{1} \leftarrow S_{0}\left(\pi \pi^{*}\right)$ origins are at $32215 \mathrm{~cm}^{-1}$ and $34881 \mathrm{~cm}^{-1}$, respectively. Asterisks indicate UV wavelengths that were checked for ion signal depletion at diagnostic IR bands. the relative energies of the tautomers the $\mathrm{N} 9 \mathrm{H}$ di-amino tautomer is the most stable form, followed by the $\mathrm{N} 7 \mathrm{H}$ di-amino tautomer, at every level of calculation.

\section{Excited state lifetimes}

To obtain a measure of excited state lifetimes we performed two color pump-probe experiments, in which we resonantly excited the molecule to the $\mathrm{S}_{1}$ state, followed by ionization out of the excited state with a $266 \mathrm{~nm}$ photon from a second laser, with a variable delay between the two pulses. Fig. 6 shows the results for 2,6-DAPu. Fitting the decay curves with a single exponential decay, we obtained excited state lifetimes of $6.3 \pm 0.4 \mathrm{~ns}$ for the $\mathrm{N} 9 \mathrm{H}$ tautomer and $8.7 \pm 0.8 \mathrm{~ns}$ for the $\mathrm{N} 7 \mathrm{H}$ tautomer. Using laser pulses of about $5 \mathrm{~ns}$ pulse width imposes a lower limit of the order of a few nanoseconds on these lifetime measurements.

In the case of 2,4-DAPy, the lifetime is shorter than this experimental limit so we were unable to perform two-color experiments and our attempts to carry out UV-UV double resonance experiments also failed. In this case we can use the peak width in the R2PI spectrum to obtain a rough estimate of the lower limit of the excited state lifetime. Fig. 7 shows the peak at $34720 \mathrm{~cm}^{-1}$ together with simulations of the rotational envelope with different Lorentzian linewidths. The simulated lineshapes assume a dominantly b-type transition and a rotational temperature of $20 \mathrm{~K}$. These parameters are consistent with our simulations of the peaks in the 2,6-DAPur spectrum, for which the width is constrained by the experimental resolution only and not by lifetime broadening. The results, as shown in Fig. 7, suggest an upper limit to the linewidth of $0.5 \mathrm{~cm}^{-1}$ corresponding to a lower limit of the excited state lifetime of $10 \mathrm{ps}$. Therefore, we can bracket the experimental window of our lifetime measurements for 2,4-DAPy roughly between $10^{-11}$ and $10^{-9} \mathrm{~s}$. This is clearly shorter than that of 2,6-DAPur, but it is longer than the lifetimes of 1.8 or 2.4 ps and 5.2 or $6.4 \mathrm{ps,} \mathrm{reported} \mathrm{for} \mathrm{uracil} \mathrm{and} \mathrm{thymine,} \mathrm{respectively,}$ with excitation at $267 \mathrm{~nm} .{ }^{99}$ We also note that the UV spectra of uracil and thymine are broad while that of 2,4-DAPy is sharp. ${ }^{5}$

This lifetime is clearly shorter than that of 2,6-DAPu, but consistent with that of other pyrimidine bases excited at the band origin. ${ }^{100,101}$ Not surprisingly, this $10 \mathrm{ps}-1$ ns time range spans values much longer than the typical 1-6 ps found for pyrimidine bases excited close to the first band maximum, well above any barriers towards conical intersections. ${ }^{9,99}$ The subnanosecond lifetime of band-origin excited 2,4-DAPy is a strong indication that this molecule deactivates by means of internal conversion just like 4-APy does. In order to examine how the internal conversion takes place, we carried out extensive analysis of the excited-state surfaces of this molecule, which will be discussed in the next section.

\section{Excited-state analysis of 2,4-diaminopyrimidine}

Stationary points in the ground and excited states. Table 4 shows the vertical excitation energies calculated at the CASSCF, MR-CISD, and CASPT2 levels. At the CASSCF level, the first excited state is of $\pi \pi^{*}$ character while the second excited state is due to excitation from the lone pairs located on 
Table 3 Calculated vibrational frequencies for tautomers of 2,6-diaminopurine in the $\mathrm{N}-\mathrm{H}$ region. All frequencies have been scaled and given in $\mathrm{cm}^{-1}$. MP2 scaling factor: 0.9496; B3LYP scaling factor: 0.9618. For numbering scheme see Fig. 1. For comparison, the experimental vibrational frequencies are $3450,3460,3509,3566$, and $3576 \mathrm{~cm}^{-1}$ (UV probe $\left.34881 \mathrm{~cm}^{-1}\right)$, and $3428,3460,3513,3533$, and $3575 \mathrm{~cm}^{-1}(\mathrm{UV}$ probe $\left.32215 \mathrm{~cm}^{-1}\right)$

\begin{tabular}{|c|c|c|c|}
\hline Tautomer & MP2 6-311+G(2d,p) $\omega / \mathrm{cm}^{-1}$ & B3LYP $6-311+\mathrm{G}(2 \mathrm{~d}, \mathrm{p}) \omega / \mathrm{cm}^{-1}$ & Vib. Mode \\
\hline 9H-26DAP & 3505 & 3577 & $\mathrm{~N} 11 \mathrm{H}$ as \\
\hline \multirow[t]{4}{*}{ diamino tautomer } & 3498 & 3567 & $\mathrm{~N} 10 \mathrm{H}$ as \\
\hline & 3438 & 3512 & N9H \\
\hline & 3380 & 3456 & $\mathrm{~N} 11 \mathrm{H} \mathrm{s}$ \\
\hline & 3379 & 3452 & $\mathrm{~N} 10 \mathrm{H} \mathrm{s}$ \\
\hline 7H-26DAP & 3493 & 3564 & $\mathrm{~N} 10 \mathrm{H}$ as \\
\hline \multirow{4}{*}{ diamino tautomer } & 3454 & 3519 & $\mathrm{~N} 11 \mathrm{H}$ as $+\mathrm{N} 7 \mathrm{H}$ \\
\hline & 3356 & 3515 & $\mathrm{~N} 7 \mathrm{H}+\mathrm{N} 11 \mathrm{H} \mathrm{s}$ \\
\hline & 3375 & 3449 & $\mathrm{~N} 10 \mathrm{H} \mathrm{s}$ \\
\hline & 3346 & 3417 & $\mathrm{~N} 11 \mathrm{H} \mathrm{s}$ \\
\hline \multirow[t]{5}{*}{$1,9 \mathrm{H}, 11$ imino } & & 3525 & $\mathrm{~N} 11 \mathrm{H}$ as \\
\hline & & 3507 & N9H \\
\hline & & 3453 & $\mathrm{~N} 1 \mathrm{H}$ \\
\hline & & 3426 & $\mathrm{~N} 10 \mathrm{H} \mathrm{s}$ \\
\hline & & 3377 & $\mathrm{~N} 11 \mathrm{H}$ \\
\hline \multirow[t]{5}{*}{$1,7 \mathrm{H}, 11$ imino } & & 3508 & N7H \\
\hline & & 3500 & $\mathrm{~N} 10 \mathrm{H}$ as \\
\hline & & 3465 & $\mathrm{~N} 1 \mathrm{H}$ \\
\hline & & 3406 & $\mathrm{~N} 10 \mathrm{H} \mathrm{s}$ \\
\hline & & 3351 & $\mathrm{~N} 11 \mathrm{H}$ \\
\hline \multirow[t]{5}{*}{$3,9 \mathrm{H}, 10$ imino } & & 3586 & $\mathrm{~N} 11 \mathrm{H}$ as \\
\hline & & 3512 & $\mathrm{~N} 9 \mathrm{H}$ \\
\hline & & 3486 & $\mathrm{~N} 3 \mathrm{H}$ \\
\hline & & 3460 & $\mathrm{~N} 11 \mathrm{H} \mathrm{s}$ \\
\hline & & 3391 & $\mathrm{~N} 10 \mathrm{H}$ \\
\hline \multirow[t]{5}{*}{$1,9 \mathrm{H}, 10$ imino } & & 3543 & $\mathrm{~N} 11 \mathrm{H}$ as \\
\hline & & 3511 & N9H \\
\hline & & 3460 & $\mathrm{~N} 1 \mathrm{H}$ \\
\hline & & 3437 & $\mathrm{~N} 11 \mathrm{H} \mathrm{s}$ \\
\hline & & 3392 & $\mathrm{~N} 10 \mathrm{H}$ \\
\hline \multirow[t]{5}{*}{$3,7 \mathrm{H}, 10$ imino } & & 3522 & $\mathrm{~N} 11 \mathrm{H}$ as $+\mathrm{N} 7 \mathrm{H}$ \\
\hline & & 3520 & $\mathrm{~N} 7 \mathrm{H}+\mathrm{N} 11 \mathrm{H}$ as \\
\hline & & 3484 & $\mathrm{~N} 3 \mathrm{H}$ \\
\hline & & 3417 & $\mathrm{~N} 11 \mathrm{H} \mathrm{s}$ \\
\hline & & 3390 & $\mathrm{~N} 10 \mathrm{H}$ \\
\hline \multirow[t]{5}{*}{$1,7 \mathrm{H}, 10$ imino } & & 3516 & $\mathrm{~N} 11 \mathrm{H}$ as \\
\hline & & 3485 & $\mathrm{~N} 7 \mathrm{H}$ \\
\hline & & 3460 & $\mathrm{~N} 1 \mathrm{H}$ \\
\hline & & 3422 & $\mathrm{~N} 11 \mathrm{H} \mathrm{s}$ \\
\hline & & 3392 & $\mathrm{~N} 10 \mathrm{H}$ \\
\hline
\end{tabular}

the nitrogen atoms of the pyrimidine ring ( $n \pi *$ transition). The calculated energy gap between these states is $0.34 \mathrm{eV}$. We obtained the same ordering of states at the CASPT2 and RICC2 levels, with a smaller energy gap amounting to 0.2 and $0.1 \mathrm{eV}$, respectively. Increasing the flexibility of the basis set does not change the ordering of the states and the energy gap between them (see Table 4 and Supplementary Material for CASPT2 and RICC2 results, respectively). At the MR-CISD + Q level the ordering is reversed with an energy gap of $0.3 \mathrm{eV}$.

The experimentally measured excitation energy at the band origin is $4.27 \mathrm{eV}$. To estimate the energy of the band maxima we have performed a simulation of the absorption spectra (see Fig. 8 for the absorption spectrum simulated with RICC2 method). From the figure we calculated the energy difference between the band maximum and band origin as $0.63 \mathrm{eV}$ (the same result was obtained employing the CASSCF method). Adding this shift to the experimental value of the band origin results in a band maximum at $4.91 \mathrm{eV}$, in a good agreement with the calculated vertical excitation energies.
We found two minima on the $S_{1}$ surface (Fig. 9a) using CASSCF optimization, with energies of 4.75 and $5.08 \mathrm{eV}$ above the ground state minimum (Table 4). Both structures show a distortion from the planarity of the ring which is more pronounced in the latter case. For both minima, the CASSCF wavefunctions show strong coupling between the $n \pi^{*}$ and $\pi \pi^{*}$ configurations with almost equal weight. Unlike the case of 4-aminopyrimidine, ${ }^{29,30}$ we did not succeed in locating a third minimum which is planar and of $\pi \pi^{*}$ character. Any attempt to find this minimum ended up in conformation S1min_C6.

The energy ordering of S1min_C6 and S1min_C2 remains the same at the MR-CISD $(8)+\bar{Q}$ level and at the CASPT2 level with an energy gap of about 0.2 and $0.3 \mathrm{eV}$, respectively. The energy ordering is reversed when 17 orbitals are frozen in the CI procedure, with the energetic changes being, however, quite small. The latter calculations place the S1min_C2 below the S1min_C6 by about $0.2 \mathrm{eV}$. The difference between the results with 8 and 17 orbitals frozen is however not significant for the discussion of reaction paths calculated by means of linear interpolation curves and, thus, the less accurate but 

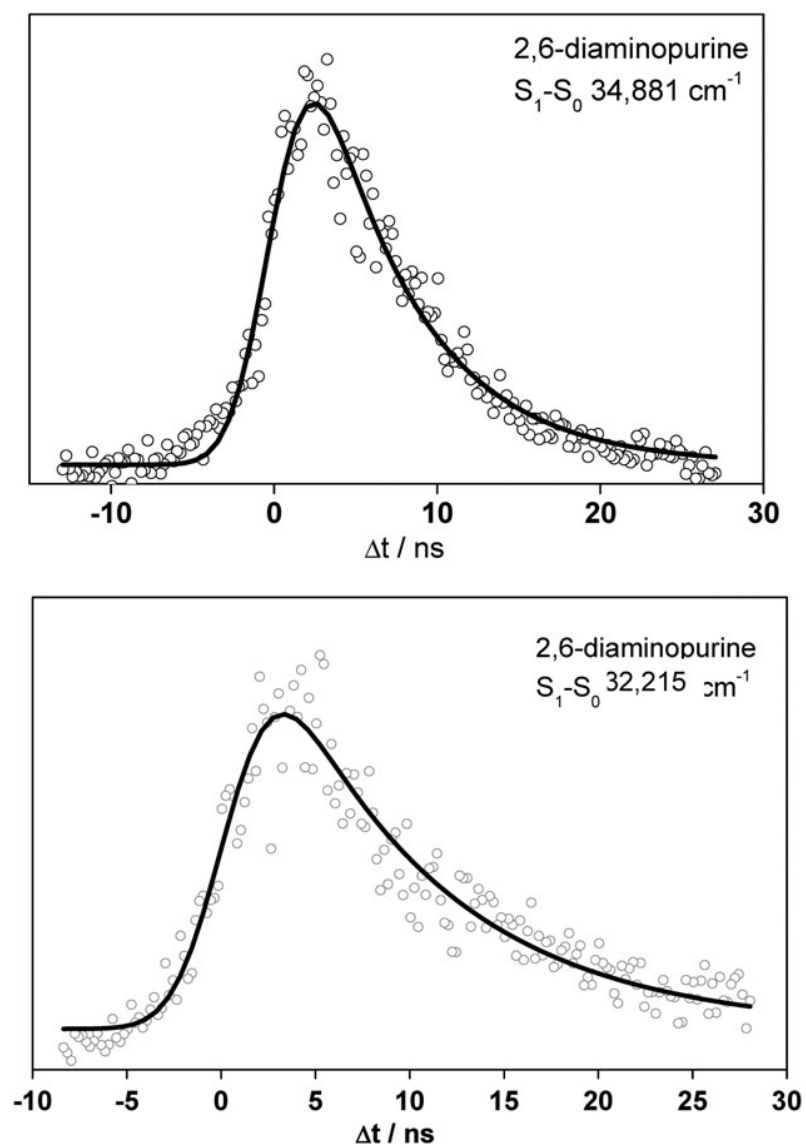

Fig. 6 Exponential decay of the ion signal of 2,6-diaminopurine in the two-color R2PI experiment. The extracted lifetime of the excited state is $8.7 \pm 0.8 \mathrm{~ns}$ for the $7 \mathrm{H}$ tautomer and $6.3 \pm 0.3 \mathrm{~ns}$ for the $9 \mathrm{H}$ tautomer.

more computationally feasible approach with 17 orbitals frozen can be used.

There is a substantial energetic relaxation of the first excited states when moving from the Franck-Condon region to the S1min_C6 and S1min_C2 optimized structures. This result is consistent with the experimentally observed low intensity of the $0-0$ transition. Although the amount of relaxation energy from $2^{1} \mathrm{~A}$ into the S1min_C2 structure, calculated with different methods, is not as uniform as in the case of relaxation into the S1min_C6 structure (see Table 4), results for all methods used show that both minima located on the $S_{1}$ surface are energetically accessible from the Franck-Condon region.
Minima on the crossing seam. Table 4 lists the CASSCF and MR-CISD energies and the character of five different minima located on the $\mathrm{S}_{0} / \mathrm{S}_{1}$ crossing seam optimized at the CASSCF level; Fig. 9b shows the corresponding structures. All structures display strong out-of-plane deformations with the twist around either the $\mathrm{CN}$ or $\mathrm{CC}$ bonds. We adopted the CremerPople classification scheme in performing the conformational analysis of these structures. ${ }^{102,103}$ Using this approach, we identified four types of structure deformations, in particular screw-boat (S), boat (B), half-chair $(\mathrm{H})$ and envelope $(\mathrm{E})$ conformations. The ${ }^{3} \mathrm{H}_{4},{ }^{1} \mathrm{~S}_{2},{ }^{1} \mathrm{~S}_{6}$ and $\mathrm{B}_{14}$ MXSs are energetically grouped closely together at the CASSCF level within $0.4 \mathrm{eV}$; all MXSs shown are energetically accessible starting from the Franck-Condon region. The structures and the energetics of all MXS points are very similar to those found by Barbatti et $a .^{29,30}$ for 4-aminopyrimidine although the results of conformational analysis are not the same (see Table 4). This situation indicates that there is only a small (if any) energetic effect of the additional amino group on the puckering of the pyrimidine ring and subsequent formation of conical intersection.

In all cases there are two major configurations which contribute to the CASSCF wavefunction $\left(\pi \pi^{*}\right.$ and $\left.n \pi^{*}\right)$ (see Table 4). Although it is difficult to distinguish lonepair and $\pi$ orbitals in such distorted structures, the main character of the singly occupied orbitals is indicated in the Table 4 . The second configuration contributing to the wavefunction in all cases is the closed-shell configuration (CS). In agreement with the results found for 4-aminopyrimidine, the character of the singly occupied orbital was identified as $\pi$ orbital.

We performed MR-CISD calculations with 8 and 17 orbitals frozen in the CI procedure. The MR-CI and CASPT2 procedures resulted in relatively large splittings, usually around $0.8 \mathrm{eV}$, of the $\mathrm{S}_{0}$ and $\mathrm{S}_{1}$ surfaces at the MXS points determined at the CASSCF level. We estimated the energies and MXS structures at the MR-CISD level from an extrapolation of the LIIC curves (these results are obtained from the MR-CISD(17)+Q calculations, see below). Table 4 lists the CASSCF and these estimated MR-CISD(17) $+\mathrm{Q}$ results. When the dynamic correlation is included, there is a change in the ordering of various MXS structures and the ${ }^{1} \mathrm{~S}_{2}$ structure becomes the most stable one. However, all structures are placed in a relatively small energy range, with the difference between the most and least stable structure $0.8 \mathrm{eV}$, in good agreement with the results of 4-aminopyrimidine.

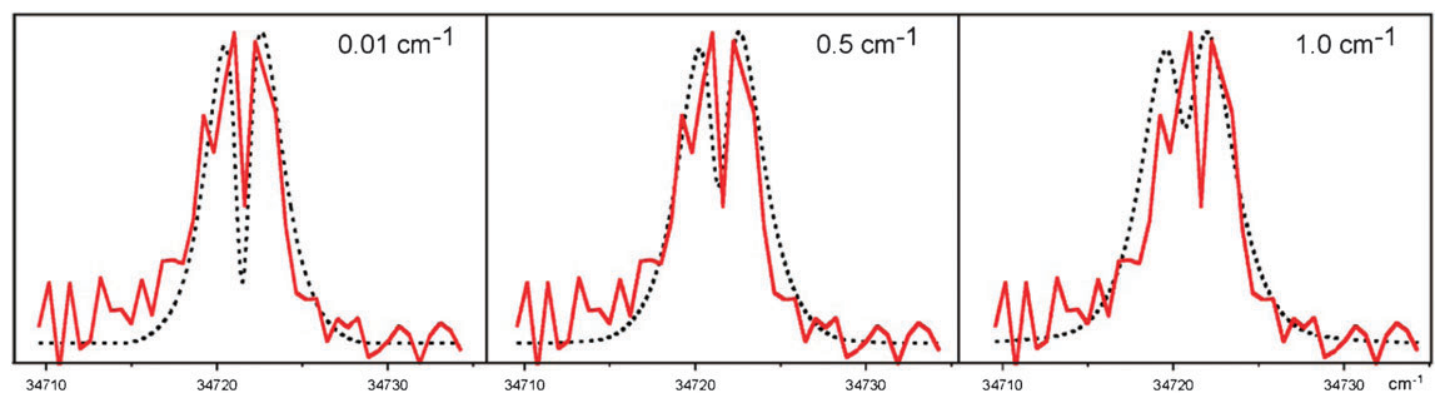

Fig. 7 Detail of the $34720 \mathrm{~cm}^{-1}$ peak in the 2,4-DAPy REMPI spectrum, compared with simulations of the rotational envelope at three different Lorentzian linewidths. 
Table 4 Energies (in eV) of stationary points and conical intersections for 2,4-diaminopyrimidine relative to the ground state minimum structure calculated at the CASSCF $(14,10)$, MR-CISD $(6,5)+Q$ and CASPT2 levels and comparison with 4-aminopyrimidine. The 6-31G** basis set was used. The experimental excitation energy (band maximum) was estimated to be $4.91 \mathrm{eV}^{a}$

\begin{tabular}{|c|c|c|c|c|c|}
\hline & & CASSCF & $\operatorname{MR}-\operatorname{CISD}(17)+\mathrm{Q}^{b}$ & $\mathrm{CASPT}^{c}$ & 4AP ${ }^{d}$ MR-QDPT2 \\
\hline $2^{1} \mathrm{~A}\left(\pi \pi^{*}\right)$ & $\begin{array}{l}\Delta E \\
f^{e}\end{array}$ & $\begin{array}{l}5.189 \\
0.065\end{array}$ & $5.420(5.406)$ & $\begin{array}{l}5.024(4.938) \\
0.063\end{array}$ & $4.79(5.34)$ \\
\hline $3{ }^{1} \mathrm{~A}\left(n \pi^{*}\right)$ & $f^{e}$ & $\begin{array}{l}5.028 \\
0.013\end{array}$ & $5.044(5.142)$ & $\begin{array}{l}5.204(5.110) \\
0.012\end{array}$ & $4.71(5.88)$ \\
\hline $\begin{array}{l}\text { S1min_C6 } \\
\text { S1min_C2 }\end{array}$ & $\begin{array}{l}\pi \pi^{*}+n \pi^{*} \\
\pi \pi^{*}+n \pi^{*}\end{array}$ & $\begin{array}{l}4.754 \\
5.075\end{array}$ & $\begin{array}{l}4.743(4.708) \\
4.632(4.917)\end{array}$ & $\begin{array}{l}4.573(4.528) \\
4.831(4.822)\end{array}$ & $\begin{array}{l}4.22(4.93) \\
4.33(5.02)\end{array}$ \\
\hline $\begin{array}{l}\operatorname{MXS}\left({ }^{3} \mathrm{H}_{4}\right) \\
\operatorname{MXS}\left({ }^{1} \mathrm{~S}_{2}\right) \\
\operatorname{MXS}\left({ }^{1} \mathrm{~S}_{6}\right) \\
\operatorname{MXS}\left({ }^{B} B_{1,4}\right) \\
\operatorname{MXS}\left({ }^{6} \mathrm{E}\right)\end{array}$ & $\begin{array}{l}\mathrm{CS}+\pi \pi^{*} \\
\mathrm{CS}+\pi \pi^{*} \\
\mathrm{CS}+\pi \pi^{*} \\
\mathrm{CS}+\pi \pi^{*} \\
\mathrm{CS}+\pi \pi^{*}\end{array}$ & $\begin{array}{l}4.594 \\
4.645 \\
4.759 \\
4.949 \\
5.328\end{array}$ & $\begin{array}{l}4.2^{f} \\
3.9^{f} \\
4.5^{f} \\
4.1^{f} \\
4.7^{f}\end{array}$ & $\begin{array}{l}4.3(4.4)^{f} \\
4.2(4.2)^{f} \\
4.5(4.5)^{f} \\
4.3(4.3)^{f}\end{array}$ & $\begin{array}{l}4.62(4.60)^{g} \\
4.36(4.49)^{h} \\
4.71(4.79) \\
(4.97) \\
(5.42)\end{array}$ \\
\hline
\end{tabular}

${ }^{a}$ For estimation of the experimental band maximum see text. ${ }^{b}$ The results with eight frozen orbitals are given in parentheses. ${ }^{c}$ The results obtained with the 6-311G(2d,p) basis set are given in parentheses. ${ }^{d}$ MR-QDPT2 energies (CASSCF energies are given in parentheses) calculated for the relevant structures of 4 -aminopyrimidine. ${ }^{e}$ Oscillator strength. ${ }^{f}$ Estimated from an extrapolation of the LIIC curves. ${ }^{g}$ Assigned as ${ }^{3} \mathrm{~S}_{4}$ for 4-APy. ${ }^{h}$ Assigned as $\mathrm{E}_{2}$ for 4-APy.

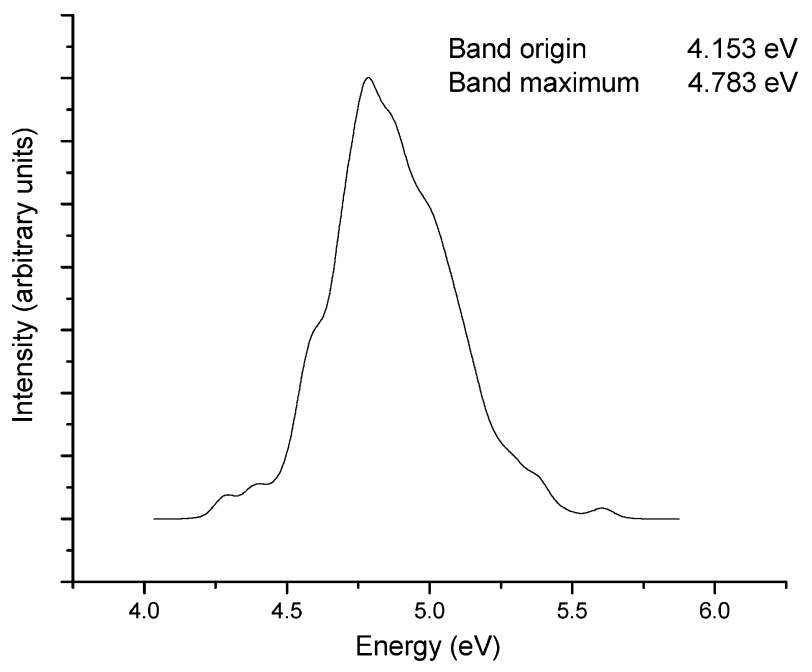

Fig. 8 Absorption spectrum of 2,4-DAPy calculated at the RICC2 method using the SVP basis set.

The CASPT2 energies, also estimated from the LIIC curves, agree reasonably well with the MR-CI results. Thus, the inclusion of the dynamic correlation effects does not change the parameters for prediction of the dynamics of the molecular systems studied.

Interpolation curves. We calculated LIIC curves for the reaction paths between the S1min_C2 and S1min_C6 minima and the four lowest MXS structures at the CASSCF and MR-CISD levels. The LIIC curve for the reaction path S1min_C6 to ${ }^{1} \mathrm{~S}_{6}$ was calculated using the CASPT2 method as well. (See Fig. 10 for the reaction path between S1min_C6 and ${ }^{1} \mathrm{~S}_{6}$. Other reaction paths are reported in the ESI). $\dagger$ To make the studies of reaction paths computationally more feasible we performed MR-CISD calculations with 17 frozen orbitals. A comparison of the character of the interpolation curves calculated at the MR-CISD(8) $+\mathrm{Q}$ and MR-CISD(17) $+\mathrm{Q}$ levels for the reaction path between S1min_C6 and ${ }^{1} \mathrm{~S}_{6}$ (see Fig. 10 and ESI) $\dagger$ shows (a) $S_{1}$ minima

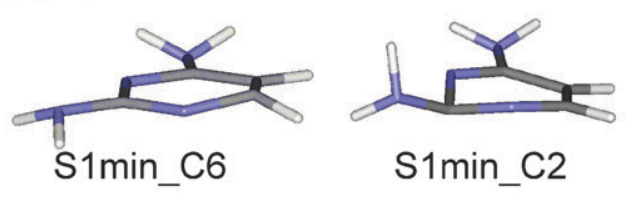

(b) $S_{1} / S_{0} M X S$
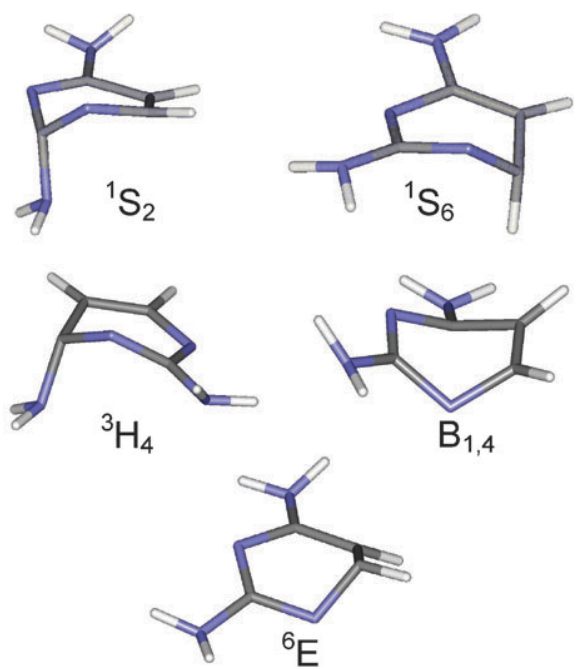

Fig. 9 (a) Structures of the two minima found on the $S_{1}$ potential energy surface optimized at the $\operatorname{CASSCF}(14,10) / 6-31 G^{* *}$ level. (b) Structures of the five different minima located on the $\mathrm{S}_{0} / \mathrm{S}_{1}$ crossing seam optimized at the CASSCF $(14,10) / 6-31 G^{* *}$ level.

that the characters of the interpolation curves are very similar justifying the use of the latter approach. The barriers for the reaction paths estimated from the highest point of the interpolation curves are presented in Table 5. These values are similar to those found by Zechmann and Barbatti for 4-APy. ${ }^{104}$ Since this estimation provides only an upper bound for the reaction barrier, we have optimized the transition states along the selected reaction paths, particularly the paths from 


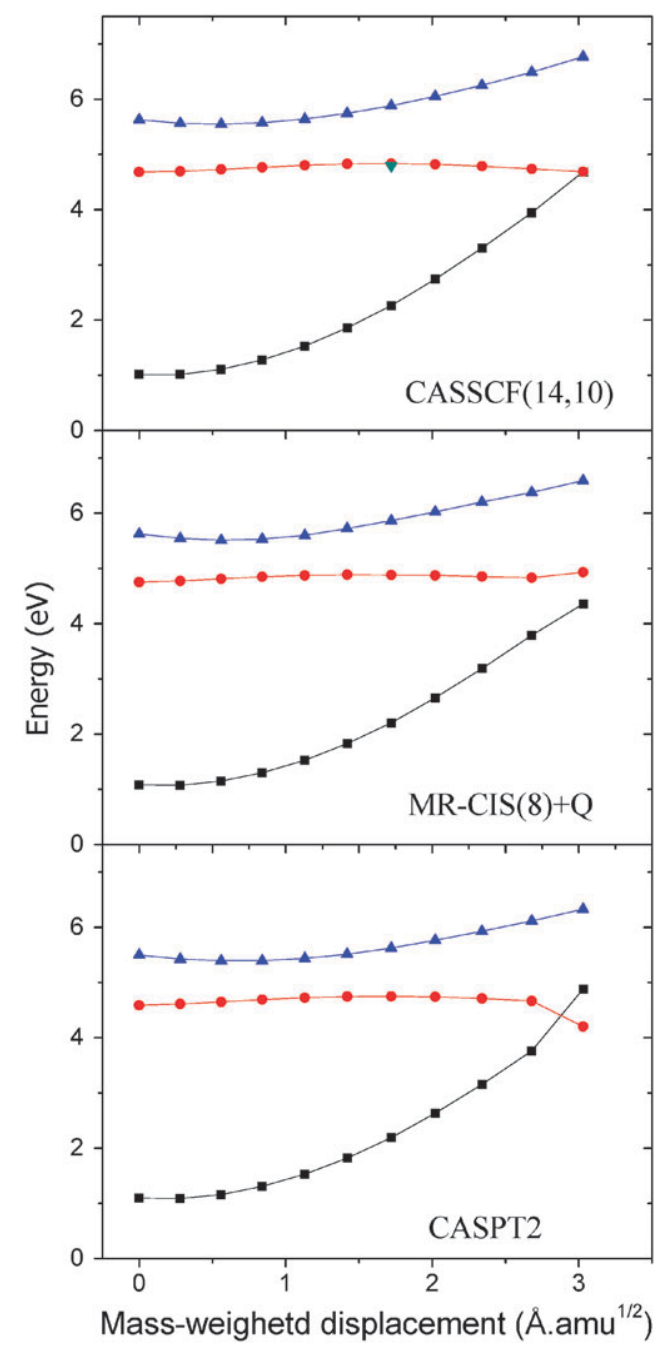

Fig. 10 Reaction path between S1min_C6 and ${ }^{1} \mathrm{~S}_{6}$ calculated using CASSCF $(14,10)$, MR-CISD(8) $+\mathrm{Q}$, and CASPT2 methods. Other reaction paths are reported in the ESI. $\dagger$

S1min_C6 towards ${ }^{1} \mathrm{~S}_{6}$ and ${ }^{3} \mathrm{H}_{4} \mathrm{MXS}$ structures. The energies of those structures are indicated in the graphs (see ESI) $\dagger$ and in Table 5 .

Relatively small barriers exist for the reaction paths between the S1min_C6 and the ${ }^{1} \mathrm{~S}_{6}$ and $\mathrm{B}_{1,4}$ and ${ }^{3} \mathrm{H}_{4} \mathrm{MXSs}$. The only sizeable barrier we found was for the reaction paths toward the ${ }^{1} \mathrm{~S}_{2}$ structure. This finding reflects some immobilization of the ring by substitution of the hydrogen atom by an amino group at the C2 atom. The barriers connecting the S1min_C2 with MXSs are generally larger with values of approximately
$0.8 \mathrm{eV}$. Starting from the highest points of the interpolation curves we determined the true saddle points for the reaction paths towards the ${ }^{1} \mathrm{~S}_{6}$ and ${ }^{3} \mathrm{H}_{4}$ structures. At the CASSCF and MR-CISD(17) $+\mathrm{Q}$ levels these calculations reduced the reaction barriers to 0.17 and $0.12 \mathrm{eV}$ at for ${ }^{3} \mathrm{H}_{4}$, and to 0.04 and $0.02 \mathrm{eV}$ for ${ }^{1} \mathrm{~S}_{6}$, respectively, indicating that both conical intersections should be easily accessible leading to a subsequent ultrafast deactivation to the ground state.

Comparing the results for 2,4-DAPy and those previously reported for 4-APy shows that the additional amino-group on the pyrimidine ring does not significantly influence the energetics of the stationary points and conical intersections, as well as the characters of interpolation curves. The only exception is the ${ }^{1} \mathrm{~S}_{2}$ structure and the interpolation curve towards it, as a result of an immobilization of the pyrimidine ring at the C2 position. Since 4-APy usually does not access the pathway with $\mathrm{C} 2$ atom deformation, one would not expect significant differences in the dynamics of these two systems, provided comparable initial conditions are used. Therefore, in analogy to the previously described surface hopping dynamics for 4-APy, the present reaction pathways for 2,4-DAPy indicate that ultrafast internal conversion to the ground state should be expected provided that sufficient initial kinetic energy is available to surpass the small energy barriers to the ${ }^{1} \mathrm{~S}_{6}$ and ${ }^{3} \mathrm{H}_{4}$ conical intersections.

In the current experiments, the pump energy is in the range of 34000 to $35000 \mathrm{~cm}^{-1}$ which corresponds to $4.2-4.3 \mathrm{eV}$. Neglecting any vibrational corrections, this energy range is close to or even below the calculated energies of the saddle points (using the CASPT2 energies of MXSs and energy barriers of the relevant saddle points collected in Table 4). Therefore, the pump energy used in the experiment is not sufficient to overcome the barrier to reach the conical intersections, producing the much longer lifetime experimentally observed for 2,4-DAPy.

When the relevant coordinates involve ring deformations, lifetimes can be significantly different for specific structures. In particular, if deformation involving C5 and C6 leads to internal conversion in 2,4-DAPy then that pathway would be significantly altered for 2,6-DAPu, in which the puckering at C6 is strongly hindered. This observation explains why the lifetime for $9 \mathrm{H}$-adenine is longer than that calculated for 4-APy and also explains the very long lifetime (6-8 ns) for 2,6-DAPu, in which both the $\mathrm{C} 2$ position and the $\mathrm{C} 5=\mathrm{C} 6$ positions are modified. In this latter case the subtle difference between the $\mathrm{N} 7 \mathrm{H}$ and $\mathrm{N} 9 \mathrm{H}$ tautomer lifetimes requires further analysis. This effect of immobilization of the $\mathrm{C} 5=\mathrm{C} 6$ twist is analogous to the findings of Zgierski et al., which showed that

Table 5 Barriers (in eV) located on the interpolation curves

\begin{tabular}{lll}
\hline & CASSCF & CISD(17)+Q \\
\hline S1min_C6 to ${ }^{1} \mathrm{~S}_{6}$ & 0.145 Saddle point: 0.040 & 0.082 Saddle point: 0.024 \\
S1min_C6 to $\mathrm{B}_{1,4}$ & 0.419 & 0.153 \\
S1min_C6 to ${ }^{3} \mathrm{H}_{4}$ & 0.407 Saddle point: 0.174 & 0.251 Saddle point: 0.118 \\
S1min_C6 to ${ }^{1} \mathrm{~S}_{2}$ & 1.041 & 1.042 \\
S1min_C2 to ${ }^{1} \mathrm{~S}_{2}$ & 0.614 & 0.976 \\
S1min_C2 to $\mathrm{B}_{1,4}$ & 0.686 & 0.974 \\
S1min_C2 to ${ }^{1} \mathrm{~S}_{6}$ & 0.788 & 0.830 \\
S1min_C2 to ${ }^{3} \mathrm{H}_{4}$ & 0.870 & 0.857
\end{tabular}


in solution 5,6-trimethylenecytosine and 5,6-trimethyleneuracil do not exhibit subpicosecond excited-state lifetimes characteristic of the naturally occurring pyrimidine bases. ${ }^{21}$

\section{Conclusions}

We recorded resonant two-photon ionization spectra of 2,4diaminopyrimidine and 2,6-diaminopurine in the frequency range of 32000 to $36000 \mathrm{~cm}^{-1}$. IR-UV double resonance experiments supported by DFT and $a b$ initio calculations suggest that we observed the most stable tautomers of both compounds. We also recorded and assigned the photoelectron spectrum of 2,4-diaminopyrimidine, placing the adiabatic ionization potential at $7.86 \pm 0.05 \mathrm{eV}$, and the first vertical ionization potential at $8.30 \pm 0.04 \mathrm{eV}$. The $\mathrm{S}_{1} \leftarrow \mathrm{S}_{0}\left(\pi \pi^{*}\right)$ origin of 2,4-diaminopyrimidine, as measured with one-color, two-photon resonant ionization, is $34459 \mathrm{~cm}^{-1}$. The excited state lifetime measured at this pump wavelength is shorter than the time resolution (approx. $1 \mathrm{~ns}$ ) of the instrument and longer than $10 \mathrm{ps}$, based on the sharp and resolved peaks in the R2PI spectrum.

According to the IR-UV double resonance experiments, both the $\mathrm{N} 7 \mathrm{H}$ and $\mathrm{N} 9 \mathrm{H}$ tautomers of 2,6-diaminopurine are easily observable in the cold jet. The $\mathrm{S}_{1} \leftarrow \mathrm{S}_{0}\left(\pi \pi^{*}\right)$ origin is at $32215 \mathrm{~cm}^{-1}$ for the $\mathrm{N} 7 \mathrm{H}$ tautomer and $34881 \mathrm{~cm}^{-1}$ for the $\mathrm{N} 9 \mathrm{H}$ tautomer. The measured excited state lifetime is $8.7 \pm 0.8 \mathrm{~ns}$ for the former and $6.3 \pm 0.4 \mathrm{~ns}$ for the latter.

This long lifetime is consistent with reduction of ring deformations in both the $\mathrm{C} 2$ position and the $\mathrm{C} 5=\mathrm{C} 6$ twist, affecting all conical intersections that lead to fast excited state dynamics in 4-APy.

To understand the photodynamics of 2,4-diaminopyrimidine, we carried out quantum chemical modeling. Based on the results of the relative energies of stationary points on the $S_{1}$ surface and its crossings with the ground state at MXS points, together with the nature of the interpolation curves we can expect ultrafast dynamics in the excited state of 2,4-diaminopyrimidine which is predicted to be comparable to that of 4-aminopyrimidine. The additional $\mathrm{NH}_{2}$ group in the $\mathrm{C} 2$ position blocks the path to only one of the conical intersections predicted for the analogous case of 4-aminopyrimidine, namely the one associated with ring deformation at $\mathrm{C} 2$. However, there are still other alternatives for almost barrierless access to conical intersections, associated with deformations at the $\mathrm{C} 5, \mathrm{C} 6$, and $\mathrm{N} 1$ positions. The actually observed lifetimes will depend on the chosen excitation energy which needs to be large enough to surmount the existing small energy barriers if ultrafast processes are to occur.

The present experiments show a significant reduction of the lifetime of 2,4-DAPy as compared to the nanosecond lifetimes determined for 2,6-DAPu, indicating a larger internal conversion rate for the former molecule. However, the current experiments involve a very narrow excitation window very close to the band origin, and therefore exhibit the longest possible lifetime. The pump energies in the range of 34000 to $35000 \mathrm{~cm}^{-1}$ are close to or possibly just below the computed energy barriers, which explains the still rather large lifetime of 2,4-DAPy compared to that of other pyrimidine bases excited at the center of the absorption band.

\section{Acknowledgements}

This study is based upon work supported by National Science Foundation (CHE-0911564), and Hungarian National Science Fund (OTKA T60669, F61153). Zsolt Gengeliczki gratefully acknowledges the generous support of the Rosztoczy Foundation. This work was supported by grants from the Ministry of Education of the Czech Republic (Center for Biomolecules and Complex Molecular Systems, LC512). It was part of research project Z40550506 and by the Austrian Science Fund within the framework of the Special Research Program F16 (Advanced Light Sources) and Project P18411-N19. Support from the Preamium Academiae, Academy of Sciences of the Czech Republic, awarded to $\mathrm{PH}$ in 2007, is gratefully acknowledged.

\section{References}

1 C. M. Marian, J. Phys. Chem. A (USA), 2007, 111, 1545-1553.

2 K. Seefeld, R. Brause, T. Haber and K. Kleinermanns, J. Phys. Chem. A (USA), 2007, 111, 6217-6221.

3 A. Abo-Riziq, L. Grace, E. Nir, M. Kabelac, P. Hobza and M. S. de Vries, Proc. Natl. Acad. Sci. U. S. A., 2005, 102, 20-23.

4 A. L. Sobolewski, W. Domcke and C. Hättig, Proc. Natl. Acad. Sci. U. S. A., 2005, 102, 17903-17906.

5 B. B. Brady, L. A. Peteanu and D. H. Levy, Chem. Phys. Lett., 1988, 147, 538-543.

6 D. C. Luhrs, J. Viallon and I. Fischer, Phys. Chem. Chem. Phys., 2001, 3, 1827-1831.

7 H. Kang, B. Jung and S. K. Kim, J. Chem. Phys., 2003, 118, 6717-6719.

8 C. Z. Bisgaard, H. Satzger, S. Ullrich and A. Stolow, ChemPhysChem, 2009, 10, 101-110.

9 C. Canuel, M. Mons, F. Piuzzi, B. Tardivel, I. Dimicoli and M. Elhanine, J. Chem. Phys., 2005, 122, 7.

10 H. R. Hudock, B. G. Levine, A. L. Thompson, H. Satzger, D. Townsend, N. Gador, S. Ullrich, A. Stolow and T. J. Martinez, J. Phys. Chem. A (USA), 2007, 111, 8500-8508.

11 T. Climent, R. Gonzalez-Luque, M. Merchan and L. SerranoAndres, Chem. Phys. Lett., 2007, 441, 327-331.

12 L. Serrano-Andres, M. Merchan and A. C. Borin, Proc. Natl. Acad. Sci. U. S. A., 2006, 103, 8691-8696.

13 S. Perun, A. L. Sobolewski and W. Domcke, J. Am. Chem. Soc., 2005, 127, 6257-6265.

14 H. Chen and S. H. Li, J. Phys. Chem. A (USA), 2005, 109, 8443-8446.

15 C. M. Marian, J. Chem. Phys., 2005, 122, 10.

16 N. Ismail, L. Blancafort, M. Olivucci, B. Kohler and M. A. Robb, J. Am. Chem. Soc., 2002, 124, 6818-6819.

17 L. Blancafort, B. Cohen, P. M. Hare, B. Kohler and M. A. Robb, J. Phys. Chem. A (USA), 2005, 109, 4431-4436.

18 L. Blancafort and M. A. Robb, J. Phys. Chem. A (USA), 2004, 108, 10609-10614.

19 L. Blancafort, J. Am. Chem. Soc., 2006, 128, 210-219.

20 S. Matsika, J. Phys. Chem. A (USA), 2004, 108, 7584-7590.

21 M. Z. Zgierski, S. Patchkovskii, T. Fujiwara and E. C. Lim, J. Phys. Chem. A (USA), 2005, 109, 9384-9387.

22 K. A. Kistler and S. Matsika, J. Chem. Phys., 2008, 128, 215102.

23 K. A. Kistler and S. Matsika, J. Phys. Chem. A (USA), 2007, 111, 2650-2661.

24 M. Barbatti and H. Lischka, J. Am. Chem. Soc., 2008, 130, 6831-6839.

25 A. Broo, J. Phys. Chem., 1998, A102, 526-531.

26 E. Nir, K. Kleinermanns, L. Grace and M. S. de Vries, J. Phys. Chem. A (USA), 2001, 105, 5106-5110.

27 S. Perun, A. L. Sobolewski and W. Domcke, Mol. Phys., 2006, 104, 1113-1121.

28 E. Fabiano and W. Thiel, J. Phys. Chem. A (USA), 2008, 112, $6859-6863$.

29 M. Barbatti and H. Lischka, J. Phys. Chem. A (USA), 2007, 111, 2852-2858. 
30 M. Barbatti, M. Ruckenbauer, J. J. Szymczak, A. J. A Aquino and H. Lischka, Phys. Chem. Chem. Phys., 2008, 10, $482-494$.

31 M. Barbatti, B. Sellner, A. J. A. Aquino and A. Lischka, Nonadiabatic Excited-State Dynamics of Aromatic Heterocycles: Toward the Time-Resolved Simulation of Nucleobasis, Springer Science, Business Media B.V., 2008.

32 G. F. Joyce, A. W. Schwartz, S. L. Miller and L. E. Orgel, Proc. Natl. Acad. Sci. U. S. A., 1987, 84, 4398-4402.

33 M. J. Lutz, J. Horlacher and S. A. Benner, Bioorg. Med. Chem. Lett., 1998, 8, 1149-1152.

34 M. J. Lutz, H. A. Held, M. Hottiger, U. Hubscher and S. A. Benner, Nucleic Acids Res., 1996, 24, 1308-1313.

35 J. A. Piccirilli, T. Krauch, S. E. Moroney and S. A. Benner, Nature, 1990, 343, 33-37.

36 S. Yamazaki, A. L. Sobolewski and W. Domcke, Phys. Chem. Chem. Phys., 2009, 11, 10165-10174.

37 H. J. Cleaves, K. E. Nelson and S. L. Miller, Naturwissenschaften, 2006, 93, 228-231

38 J. P. Ferris, O. S. Zamek, A. M. Altbuch and H. Freiman, J. Mol. Evol., 1974, 3, 301-309.

39 S. Miyakawa, H. J. Cleaves and S. L. Miller, Origins Life Evol. Biosphere, 2002, 32, 209-218.

40 M. P. Robertson, M. Levy and S. L. Miller, J. Mol. Evol., 1996, 43, 543.

41 R. Saladino, C. Crestini, V. Neri, J. R. Brucato, L. Colangeli, F. Ciciriello, E. Di Mauro and G. Costanzo, ChemBioChem, $2005,6,1368-1374$.

42 E. Nir, M. Muller, L. I. Grace and M. S. de Vries, Chem. Phys. Lett., 2002, 355, 59-64.

43 E. Nir, C. Janzen, P. Imhof, K. Kleinermanns and M. S. de Vries, J. Chem. Phys., 2001, 115, 4604-4611.

44 E. Nir, I. Hunig, K. Kleinermanns and M. S. de Vries, Phys. Chem. Chem. Phys., 2003, 5, 4780-4785.

45 K. A. Seefeld, C. Plutzer, D. Lowenich, T. Haber, R. Linder, K. Kleinermanns, J. Tatchen and C. M. Marian, Phys. Chem. Chem. Phys., 2005, 7, 3021-3026.

46 M. P. Callahan, B. Crews, A. Abo-Riziq, L. Grace, M. S. de Vries, Z. Gengeliczki, T. M. Holmes and G. A. Hill, Phys. Chem. Chem. Phys., 2007, 9, 4587-4591.

47 R. Tembreull, C. H. Sin, H. M. Pang and D. M. Lubman, Anal. Chem., 1985, 57, 2911-2917.

48 G. Meijer, M. S. de Vries, H. E. Hunziker and H. R. Wendt, Appl. Phys. B: Photophys. Laser Chem., 1990, 51, 395-403.

49 B. Csakvari, A. Nagy, L. Zanathy and L. Szepes, Magy. Kem. Foly., 1992, 98, 415-419.

50 A. D. Becke, J. Chem. Phys., 1993, 98, 5648-5652.

51 C. T. Lee, W. T. Yang and R. G. Parr, Phys. Rev. B: Condens. Matter, 1988, 37, 785-789.

52 B. Miehlich, A. Savin, H. Stoll and H. Preuss, Chem. Phys. Lett., 1989, 157, 200-206.

53 A. D. Mclean and G. S. Chandler, J. Chem. Phys., 1980, 72, $5639-5648$

54 R. Krishnan, J. S. Binkley, R. Seeger and J. A. Pople, J. Chem. Phys., 1980, 72, 650-654.

55 C. Moller and M. S. Plesset, Phys. Rev., 1934, 46, 618-622.

56 J. A. Pople, M. Headgordon and K. Raghavachari, J. Chem. Phys., 1989, 90, 4635-4636.

57 M. J. Frisch, M. Headgordon and J. A. Pople, Chem. Phys. Lett., 1990, 166, 275-280.

58 M. J. Frisch, M. Headgordon and J. A. Pople, Chem. Phys. Lett., 1990, 166, 281-289.

59 M. Headgordon and T. Headgordon, Chem. Phys. Lett., 1994, 220, $122-128$.

60 S. Saebo and J. Almlof, Chem. Phys. Lett., 1989, 154, 83-89.

61 M. P. Andersson and P. Uvdal, J. Phys. Chem. A (USA), 2005, 109, 2937-2941.

62 A. P. Scott and L. Radom, J. Phys. Chem., 1996, 100, 16502-16513.

63 L. A. Curtiss, K. Raghavachari, P. C. Redfern, V. Rassolov and J. A. Pople, J. Chem. Phys., 1998, 109, 7764-7776.

64 R. E. Stratmann, G. E. Scuseria and M. J. Frisch, J. Chem. Phys., 1998, 109, 8218-8224.

65 R. Bauernschmitt and R. Ahlrichs, Chem. Phys. Lett., 1996, 256, 454-464.
66 M. E. Casida, C. Jamorski, K. C. Casida and D. R. Salahub, J. Chem. Phys., 1998, 108, 4439-4449.

67 J. V. Ortiz, J. Chem. Phys., 1988, 89, 6353-6356.

68 L. S. Cederbaum, J. Phys. B: At. Mol. Phys., 1975, 8, 290-303.

69 W. von Niessen, J. Schirmer and L. S. Cederbaum, Comput. Phys. Rep., 1984, 1, 57.

70 V. G. Zakrzewski and W. Vonniessen, J. Comput. Chem., 1993, 14, 13-18.

71 V. G. Zakrzewski and J. V. Ortiz, Int. J. Quantum Chem., 1995, 53, 583-590.

72 J. V. Ortiz, Int. J. Quantum Chem., 1988, 22, 431.

73 J. V. ortiz, Int. J. Quant. Chem. Symp., 1989, 23, 321.

74 J. V. Ortiz, V. G. zakrzewski and O. Dolgounircheva, in Conceptual Perspectives in Quantum Chemistry, ed. J. L. Calais and E. S. Kryachko, Kluwer Academic, 1997, p. 465.

75 M. J. Frisch, G. W. Trucks, H. B. Schlegel, G. E. Scuseria, M. A. Robb, J. R. Cheeseman, J. Montgomery, J. A., T. Vreven, K. N. Kudin, J. C. Burant, J. M. Millam, S. S. Iyengar, J. Tomasi, V. Barone, B. Mennucci, M. Cossi, G. Scalmani, N. Rega, G. A. Petersson, H. Nakatsuji, M. Hada, M. Ehara, K. Toyota, R. Fukuda, J. Hasegawa, M. Ishida, T. Nakajima, Y. Honda, O. Kitao, H. Nakai, M. Klene, X. Li, J. E. Knox, H. P. Hratchian, J. B. Cross, V. Bakken, C. Adamo, J. Jaramillo, R. Gomperts, R. E. Stratmann, O. Yazyev, A. J. Austin, R. Cammi, C. Pomelli, J. W. Ochterski, P. Y. Ayala, K. Morokuma, G. A. Voth, P. Salvador, J. J. Dannenberg, V. G. Zakrzewski, S. Dapprich, A. D. Daniels, M. C. Strain, O. Farkas, D. K. Malick, A. D. Rabuck, K. Raghavachari, J. B. Foresman, J. V. Ortiz, Q. Cui, A. G. Baboul, S. Clifford, J. Cioslowski, B. B. Stefanov, G. Liu, A. Liashenko, P. Piskorz, I. Komaromi, R. L. Martin, D. J. Fox, T. Keith, M. A. Al-Laham, C. Y. Peng, A. Nanayakkara, M. Challacombe, P. M. W. Gill, B. Johnson, W. Chen, M. W. Wong, C. Gonzalez and J. A. Pople, Gaussian, Inc., Wallingford, CT, 2004.

76 A. Bunge, J. Chem. Phys., 1970, 53, 20

77 J. A. Pople, R. Seeger and R. Krishnan, Int. J. Quantum Chem., 1977, 149-163.

78 W. J. Hehre, R. Ditchfie and J. A. Pople, J. Chem. Phys., 1972, 56, 2257.

79 J. S. Binkley, J. A. Pople and W. J. Hehre, J. Am. Chem. Soc., 1980, 102, 939-947.

80 K. Andersson, P. A. Malmqvist and B. O. Roos, J. Chem. Phys., 1992, 96, 1218-1226.

81 K. Andersson, P. A. Malmqvist, B. O. Roos, A. J. Sadlej and K. Wolinski, J. Phys. Chem., 1990, 94, 5483-5488.

82 A. Kohn and C. Hattig, J. Chem. Phys., 2003, 119, 5021-5036.

83 C. Hattig, J. Chem. Phys., 2003, 118, 7751-7761.

84 M. Barbatti, G. Granucci, M. Persico, M. Ruckenbauer, M. Vazdar, M. Eckert-Maksic and H. Lischka, J. Photochem. Photobiol., A, 2007, 190, 228-240.

85 M. Dallos, H. Lischka, R. Shepard, D. R. Yarkony and P. G. Szalay, J. Chem. Phys., 2004, 120, 7330-7339.

86 H. Lischka, M. Dallos, P. G. Szalay, D. R. Yarkony and R. Shepard, J. Chem. Phys., 2004, 120, 7322-7329.

87 H. Lischka, M. Dallos and R. Shepard, Mol. Phys., 2002, 100, $1647-1658$

88 R. Shepard, H. Lischka, P. G. Szalay, T. Kovar and M. Ernzerhof, J. Chem. Phys., 1992, 96, 2085-2098.

89 R. Shepard, in Modern Electronic Structure Theory, ed. D. R. Yarkony, World Scientific, Singapore, 1995, vol. 1, p. 345 .

90 H. Lischka, R. Shepard, R. M. Pitzer, I. Shavitt, M. Dallos, T. Muller, P. G. Szalay, M. Seth, G. S. Kedziora, S. Yabushita and Z. Y. Zhang, Phys. Chem. Chem. Phys., 2001, 3, 664-673.

91 H. Lischka, R. Shepard, F. B. Brown and I. Shavitt, Int. J. Ouantum Chem., 1981, 91-100.

92 H. Lischka, R. Shepard, I. Shavitt, R. M. Pitzer, M. Dallos, T. Muller, P. G. Szalay, F. B. Brown, R. Ahlrichs, H. J. Boehm, A. Chang, D. C. Comeau, R. Gdanitz, H. Dachsel, C. Ehrhardt, M. Ernzefhof, P. Hoechtl, S. Irle, G. Kedziora, T. Kovar, V. Parasuk, M. J. M. Pepper, P. Sharf, H. Shiffer, M. Schindler, M. Schuler, M. Seth, E. A. Stahlberg, J.-G. Zhao, S. Yabushita, Z. Zhang, M. Barbatti, S. Matsika, M. Schuurmann, D. R. Yarkony, S. R. Brozell, E. V. Beck and 
J.-P. Blaudeau, Columbus, an ab initio electronic structure program release 5.9.1, www.univie.ac.at/columbus, 2006.

93 G. Karlstrom, R. Lindh, P. A. Malmqvist, B. O. Roos, U. Ryde, V. Veryazov, P. O. Widmark, M. Cossi, B. Schimmelpfennig, P. Neogrady and L. Seijo, Comput. Mater. Sci., 2003, 28, $222-239$.

94 P. A. Malmqvist, A. Rendell and B. O. Roos, J. Phys. Chem., 1990, 94, 5477-5482.

95 B. O. Roos and P. R. Taylor, Chem. Phys., 1980, 48, 157-173.

96 R. Ahlrichs, M. Bar, M. Haser, H. Horn and C. Kolmel, Chem Phys. Lett., 1989, 162, 165-169.

97 M. Barbatti, G. Granucci, M. Ruckenbauer, J. Pittner, M. Persico and $\mathrm{H}$. Lischka, NEWTON-X: a package for Newtonian dynamics close to the crossing seam, www.univie.ac.at/newtonx, 2007.
98 I. P. Csonka, U. Szepes and A. Modelli, J. Mass Spectrom., 2004, 39, $1456-1466$

99 H. Kang, K. T. Lee, B. Jung, Y. J. Ko and S. K. Kim, J. Am. Chem. Soc., 2002, 124, 12958-12959.

100 Y. G. He, C. Y. Wu and W. Kong, J. Phys. Chem. A (USA), 2003, 107, 5145-5148.

101 Y. G. He, C. Y. Wu and W. Kong, J. Phys. Chem. A (USA), 2004, 108, 943-949.

102 D. Cremer, Acta Crystallogr., Sect. B: Struct. Sci., 1984, 40, 498-500.

103 D. Cremer and J. A. Pople, J. Am. Chem. Soc., 1975, 97, 1354-1358.

104 G. Zechmann and M. Barbatti, Int. J. Quantum Chem., 2008, 108, 1266-1276. 